\title{
HIPERADRENOCORTICISMO CANINO: REVISÃO DE LITERATURA
}

\author{
Larissa Vieira de Paula $^{1}$, Alana Flávia Romani ${ }^{2}$, Guilherme Pinheiro Santos ${ }^{3}$, Andreia \\ Vitor do Couto Amaral ${ }^{2}$, Wanessa Ferreira Ataíde ${ }^{2}$ \\ 1. Residente, Hospital Veterinário, Universidade Federal de Jataí, Jataí, Brasil. \\ (larissa_cdo@hotmail.com) \\ 2. Docente, Medicina Veterinária, Universidade Federal de Jataí, Jataí, Brasil. \\ 3. Residente, Hospital Veterinário, Escola de Veterinária e Zootecnia, Universidade \\ Federal de Goiás, Goiânia, Brasil.

\section{Recebido em: 22/09/2018 - Aprovado em: 23/11/2018 - Publicado em: 03/12/2018 DOI: 10.18677/EnciBio_2018B52}

\begin{abstract}
RESUMO
O Hiperadrenocorticismo (HAC), ou Síndrome de Cushing, consiste em doença endócrina que acomete principalmente cães de meia idade a idosos, de qualquer raça ou sexo. Etiologicamente pode ser classificado como iatrogênico, causado pelo uso indiscriminado de glicocorticóides, ou espontâneo, subdividido em adrenaldependente e hipófise-dependente, causados por tumores nas respectivas glândulas. A sintomatologia não é patognomônica e inclui alterações dermatológicas, abdômen penduloso, atrofia muscular poliúria, polidipsia, polifagia e, em alguns casos, sinais neurológicos. Os achados laboratoriais usualmente são hiperglicemia, aumento da fosfatase alcalina e da alanina aminotransferase, proteinúria, hipercolesterolemia, hipostenúria, diminuição das concentrações séricas de ureia e creatinina e, ocasionalmente, glicosúria. O diagnóstico é feito com base na sintomatologia clínica e confirmado com testes endócrinos, como o teste de estimulação com o ACTH e o teste de supressão com dexametasona em doses baixas. A investigação etiológica é feita com base nos exames de imagem e em testes como a concentração plasmática de hormônio adrenocorticotrófico endógeno. Dentre as opções de tratamento destacam-se o trilostano e o mitotano. A abordagem cirúrgica por meio de adrenalectomia ou hipofisectomia consiste em alternativa dispendiosa e pouco utilizada na rotina. O prognóstico é baseado na etiologia do HAC, no tratamento escolhido e na adesão do tutor do animal ao tratamento. Por se tratar de endocrinopatia de ocorrência relevante na clínica médica veterinária, este trabalho de conclusão de curso tem como objetivo trazer revisão bibliográfica sobre tal síndrome.
\end{abstract}

PALAVRAS-CHAVE: glândula adrenal, glicocorticoides, hipófise.

\section{CANINE HYPERADRENOCORTICISM: REVIEW}

\begin{abstract}
Hyperadrenocorticism, or Cushing Syndrome is an endocrine disease seen mainly in average and old dogs, from any breed and sex. Etiologically can be classified as iatrogenic, caused by indiscriminate use of glycocorticoids, which is divided in adrenal dependent and hypophysis dependent caused by tumors in the ENCICLOPÉDIA BIOSFERA, Centro Científico Conhecer - Goiânia, v.15 n.28; p. $595 \quad 2018$
\end{abstract}


correspondent glands. The symptoms are not pathognomonic and include dermatologic alterations, pendulous abdomen, muscle atrophy, polyuria, polydipsia, polyphagia and neurological signs in some cases. Usually, the laboratorial findings are hyperglycemia, increase in alkaline phosphatase and aminotransferase alanine, proteinuria, hypercholesterolemia, hyposthenuria, decrease in seric concentrations of urea and creatinine, and occasionally glycosuria. The diagnosis is based on clinical symptomatology and confirmed with endocrine tests, as the stimulation with ACTH test and suppression with dexamethasone in low doses test. The etiologic investigation is done based on imaging exams and tests with a plasmatic concentration of endogen adrenocorticotrophic hormone. Among the treatment options, detaches the trilostane and mitotane. The surgical approach based on adrenalectomy or hypophysectomy consists in a dispendious and not very used alternative. The prognosis is based on the etiology of HAC and the chosen treatment and owner adhesion to the treatment. In conclusion, because it brings the theme of endocrinopathy with relevant occurance in the veterinary medical clinic, this conclusion aims to bring the literature revision about the Cushing Syndrome.

KEYWORDS: adrenal gland, glycocorticoids, hypophysis.

\section{INTRODUÇÃO}

A integração do metabolismo nos mamíferos é realizada pelos sistemas nervoso, que opera através de neurotransmissores como noradrenalina, acetilcolina ou serotonina, e endócrino que opera através de mensageiros químicos denominados hormônios, os quais são transportados pelo sangue até seu local de ação (órgão-alvo). De forma geral, os hormônios são moduladores das reações enzimáticas do metabolismo, participando de funções específicas como o crescimento celular, a regulação do metabolismo, lactação e sistema reprodutivo, por exemplo. Embora estes sistemas sejam estudados de forma separada, no estudo da regulação do metabolismo, eles atuam de forma integrada em um sistema neuroendócrino (GONZALÉZ; SILVA, 2003).

Aristóteles foi o primeiro a descrever fatos relacionados com a função endócrina, quando em 322 a.C. relatou os efeitos da castração nas aves e no homem, embora sem compreender o mecanismo. O italiano Eustáquio, em 1564, foi o primeiro a definir as glândulas adrenais, e em 1766, Von Haller propôs o conceito de órgão endócrino, sendo este cuja a secreção é vertida no sangue. Mais tarde, em 1775, Teophile Bordeu propôs com base no conceito de Von Haller, que tais secreções eram necessárias para manter a integridade do organismo. Em 1786, John Hunter transplantou testículos de aves dentro da cavidade abdominal para observar possíveis alterações no desenvolvimento do animal. Claude Bernard usou o termo "secreção interna" para diferenciar de "secreção externa" tomando como exemplo de secreção interna a glicose secretada pelo fígado para o sangue e como secreção externa a bile, secretada pelo fígado para o trato gastrointestinal. Em 1856 Brown-Séquard demonstrou experimentalmente a insuficiência adrenal por destruição cortical que havia sido proposta por Thomas Addison um ano antes. $O$ termo hormônio foi primeiro aplicado por Bayliss e Starling em 1905 como sendo uma substância produzida em um órgão endócrino e transportada no sangue para exercer sua função em outro órgão, como referência à secretina, uma substância gastrointestinal produzida pelo suco pancreático (GONZALÉZ; SILVA, 2003).

Em 1932, o Dr. Harvey Cushing descreveu 15 pacientes humanos com uma desordem caracterizada por ele como "o resultado de uma pituitária basofílica". Anos 
depois, estudos minuciosos desses e de outros casos sugeriram múltiplas causas para esta síndrome, com altas concentrações séricas de cortisol sendo o último denominador comum dessas doenças (FELDMAN et al., 2015; PÉREZ-ALENZA; MELIÁN, 2017).

O hiperadrenocorticismo (HAC) ou Síndrome de Cushing é uma das endocrinopatias mais comumente diagnosticadas em cães de meia idade e idosos, sem predisposição sexual ou racial e está associada com a produção excessiva de glicocorticóides causada por tumor de origem hipofisária ou neoplasia adrenocortical ou ainda de forma iatrogênica em virtude de administração excessiva glicocorticóides exógenos (NELSON, 2015; PÉREZ-ALENZA; MELIÁN, 2017).

A presente revisão bibliográfica pretende trazer informações essenciais sobre o hiperadrenocorticismo canino para profissionais e acadêmicos de Medicina Veterinária, uma vez que sua ocorrência na rotina clínica é significativa, sua sintomatologia inespecífica e seu diagnóstico complexo.

\section{DESENVOLVIMENTO}

\section{ANATOMOHISTOFISIOLOGIA DA GLÂNDULA ADRENAL}

No cão, as glândulas adrenais são um par de órgãos endócrinos, localizadas no tecido retroperitoneal ao longo dos polos craniais medianos dos rins. Anatomicamente são divididas em região cortical, que é externa, com origem mesodérmica, e região medular, interna, de origem ectodérmica, (GONZALÉZ; SILVA, 2003; BEHREND, 2015).

Histologicamente, o córtex é constituído por três zonas distintas. A zona glomerulosa é a mais externa, compreende cerca de $15 \%$ do córtex e é a única que possui as enzimas necessárias para a desidrogenação de 18-desoxicorticosterona. É responsável pela produção de mineralocorticoides que desempenham um papel importante no controle do equilíbrio hidroeletrolítico e, consequentemente, no controle da pressão arterial. A principal representante do grupo é a aldosterona, cuja síntese é controlada principalmente pelo sistema renina-angiotensina e pelas concentrações séricas de potássio. Nesta zona não ocorre a síntese de cortisol ou de hormônios sexuais devido à deficiência da enzima 17-alfa-hidroxilase (HERRTAGE; RAMSEY, 2015; ROMÃO et al., 2011; BEHREND, 2015; DE MARCO, 2015).

A zona fasciculada que é a intermediária, ocupa $80 \%$ do córtex e produz glicocorticoides, principalmente o cortisol. Por fim há a zona reticular, que compreende os outros $5 \%$ e é a mais interna, sendo responsável pela síntese de andrógenos e em menor grau, glicocorticóides, estrógenos e progesterona (DE MARCO, 2015). Essas zonas possuem a enzima $17 \alpha$-hidroxilase, permitindo sintetizar 17 $\alpha$-hidroxipregnenolona e 17 $\alpha$-hidroxiprogesterona, que são os componentes precursores do cortisol e androgéneos (GONZALÉZ; SILVA, 2003). A região medular encontra-se adjacente à zona reticular e compreende de 10 a $20 \%$ do volume total da glândula. Nesta região ocorre a secreção de catecolaminas, como adrenalina e noradrenalina em resposta ao estímulo simpático. Os andrógenos, dentre outras funções são responsáveis pelo início do desenvolvimento e maturação dos órgãos sexuais. (ROMÃO et al., 2011).

Os glicocorticóides, especificamente o cortisol, possuem efeitos sobre vários sistemas. No metabolismo de carboidratos, o cortisol estimula a gliconeogênese no 
fígado, aumentando o armazenamento de glicogênio hepático e diminuindo a taxa de utilização da glicose pelas células, o que leva a um aumento nos níveis glicêmicos do organismo. No metabolismo de proteínas, ele promove o catabolismo e diminuição da síntese proteica, além de deprimir o transporte de aminoácidos (aa) que associado ao catabolismo, leva ao aumento das concentrações sanguíneas de aa. O cortisol estimula a lipólise no tecido adiposo, o que resulta na liberação de ácidos graxos livres e glicerol. A insulina reage a esse efeito inibindo a lipólise e estimulando a lipogênese. A cetogênese ocorre se os efeitos da insulina forem superados. O tecido adiposo tende a ser redistribuído no abdômen e na parte posterior do pescoço em cães com excesso de concentração de glicocorticóides (KLEIN, 2014; HERRTAGE; RAMSEY, 2015).

No sistema imune, o cortisol promove supressão por meio da diminuição da permeabilidade capilar, reduzindo a migração de leucócitos e sua capacidade de digestão do material fagocitado, além de diminuir a produção de linfócitos $T$, eosinófilos e anticorpos. Nos casos de hipersensibilidade, inibe a degranulação mastocitária, a descarboxilação de histidina e impede a produção de prostaglandinas. Outros efeitos esperados são a redução da febre e o retardo do processo de cicatrização de feridas (HERRTAGE; RAMSEY, 2015).

O colesterol é o precursor na biossíntese dos esteroides adrenais. Ele é transportado por lipoproteínas de baixa densidade (LDL) e em sua maioria é esterificado e armazenado em gotas lipídicas citoplasmáticas (KLEIN, 2014). As enzimas envolvidas pertencem à família das citocromo P-450 oxigenases, encontrando-se em todas as reações enzimáticas até a produção do cortisol (GONZALÉZ; SILVA, 2003).

A primeira fase consiste na clivagem enzimática do colesterol em pregnenolona, um esteroide de 21 átomos de carbono, precursor comum a todos os esteroides, via citocromo P45017 $\alpha$ (17-hidroxilase/liase). Através da enzima 3 $\beta$ esteroide desidrogenase a pregnenolona pode dar origem a progesterona. A partir da pregnenolona ou da progesterona, várias vias são possíveis para sintetizar os demais hormônios esteroides com as enzimas 17-hidroxilase/liase, 3ß-esteroide desidrogenase, 11ß-hidroxilase e 21-hidroxilase. As hidroxilases deste sistema requerem oxigênio molecular e NADPH. A progesterona é hidroxilada na posição 21 pela ação da 21-hidroxilase para formar 11-deoxicorticosterona (DOC), composto que tem ação mineralocorticóide. Mais uma hidroxilação no DOC sobre o C-11 pela ação da $11 \beta$-hidroxilase, produz corticosterona, que tem maior ação glicocorticóide. A síntese de cortisol requer 3 hidroxilações sequenciais no C-17, C-21 e C11. Se a posição 21 for hidroxilada antes, via progesterona, a posição 17 não é mais hidroxilada e são sintetizados mineralocorticóides. Portanto, a rota mais frequente para síntese do cortisol é a $17 \alpha$-hidroxilação da pregnenolona (GONZALÉZ; SILVA, 2003; ROMÃO et al., 2011; PÉREZ-ALENZA; MELIÁN, 2017).

A biossíntese de mineralocorticoides ocorre através da enzima $18 \alpha$ hidroxilase, pois no retículo endoplasmático não há a enzima $17 \alpha$-hidroxilase. Ela atua sobre a corticosterona e produz 18-hidroxicorticosterona, a qual se trasnforma em aldosterona por ação de uma desidrogenase que converte a hidroxila do C-18 em aldeído. Esse grupo reage com $\mathrm{O}-\mathrm{OH}$ do $\mathrm{C}-11$ para estabilizar-se como hemiacetal (GONZALÉZ; SILVA, 2003; PÉREZ-ALENZA; MELIÁN, 2017).

A síntese dos glicocorticoides é estimulada pelo hormônio adrenocorticotrófico (ACTH) da hipófise através de estimulação pelo hormônio liberador da corticotropina (CRH), originado no hipotálamo (BEHREND, 2015). O 
ACTH atua sobre receptores de membrana das células do córtex adrenal estimulando a adenilciclase que promove a elevação dos níveis de cAMP, ativando a enzima proteína-quinase, que por sua vez ativa a colesterol esterase que hidrolisa ésteres de colesterol para disponibilizar colesterol livre, que por sua vez deve entrar na mitocôndria para o processo de síntese dos glicocorticoides e no retículo endoplasmático para síntese dos mineralocorticoides (GONZALÉZ; SILVA, 2003).

Assim como a síntese, a liberação dos glicocorticóides é controlada pelo $\mathrm{ACTH}$, que é liberado pela hipófise anterior e que é regulado pelo $\mathrm{CRH}$. Este é secretado por neurônios na porção anterior do núcleo paraventricular do hipotálamo e transportado via circulação portal até a hipófise. O ACTH exerce um sistema de retroalimentação negativo (feedbacknegativo) de alça curta sobre o $\mathrm{CRH}$. O ACTH liberado na corrente sanguínea estimula a liberação de cortisol pelo córtex da adrenal, aumentando as concentrações séricas deste, que tem efeitos diretos no feedback negativo sobre o hipotálamo para redução do $\mathrm{CRH}$ e sobre a hipófise para redução da síntese de ACTH. A secreção destes hormônios é episódica e pulsátil, variando assim as concentrações de cortisol durante o dia. Alguns autores alegam que no cão essas concentrações costumam ser maiores nas primeiras horas da manhã, no entanto, o ritmo circadiano do cortisol é difícil de ser confirmado em cães e gatos. Em picos de estresse o feedback negativo não ocorre, mantendo as concentrações de ACTH e cortisol elevadas, desafiando assim o sistema imunológico a liberar interleucina-1 para estimular a liberação do $\mathrm{CRH}$ (DE MARCO, 2015; HERRTAGE; RAMSEY, 2015).

\section{ETIOLOGIA}

O HAC pode ser espontâneo ou iatrogênico. Uma das formas espontâneas é o hiperadrenocorticismo hipófise-dependente ou pituitária dependente (HPD), que acomete de $80 \%$ a $85 \%$ dos cães com HAC espontâneo (PÉREZ-ALENZA; MELIAN, 2017). Cerca de $90 \%$ dos cães com HPD apresentam tumor hipofisário, o que estimula uma secreção exacerbada de ACTH, resultando em hiperplasia bilateral das adrenocorticais e excesso de secreção de cortisol. Esses tumores são geralmente adenomas das células corticotrópicas da pars distalis (70\% dos casos de HPD), nos quais o ACTH tem liberação controlada pelo $\mathrm{CRH}$; adenomas da pars intermedia (30\% dos casos de HPD), nos quais o ACTH está sobre controle neural direto, principalmente pela inibição dopaminérgica e, raramente, carcinomas funcionais da hipófise (PETERSON, 2007; HERRTAGE; RAMSEY, 2015).

Nos outros $10 \%$ dos casos de HPD ocorre uma falha no feedback negativo do cortisol sobre o ACTH ainda não bem esclarecida. Suspeita-se que possa estar associada à excessiva estimulação das células corticotrópicas da hipófise por conta de um distúrbio hipotalâmico ou ainda uma superprodução de $\mathrm{CRH}$ pelo hipotálamo, que poderia causar uma hiperplasia difusa das células corticotrópicas da hipófise anterior. Nos casos de falha no feedback, no entanto, a secreção episódica de ACTH resulta em concentrações flutuantes de cortisol, que às vezes podem estar dentro da normalidade (HERRTAGE; RAMSEY, 2015).

Os 15 a 20\% restantes dos casos de HAC espontâneos são causados por tumores adrenais uni ou bilaterais (HAC adrenal dependente - HAD), como os adenomas e carcinomas adrenocorticais (HERRTAGE; RAMSEY, 2015; NELSON, 2015). Segundo Herrtage e Ramsey (2015), estes ocorrem com frequência igual, entretanto, um estudo retrospectivo dos casos de adrenalectomia realizado por Pacini et al., (2015), revelaram através da histopatologia que $84,61 \%$ dos casos se 
tratavam de adenoma cortical e 15,39\% de adenocarcinoma.

Os carcinomas tendem a ser calcificados, ter mais de $2 \mathrm{~cm}$ de diâmetro, podendo invadir estruturas locais como os rins, fígado e veia cava, causar fibrose tecidual na sua periferia, hemorragia e necrose, além de metástase no fígado, pulmão e rim (PETERSON, 2007). Os adenomas geralmente são pequenos e bem circunscritos, não possuem tendência metastática e não são localmente invasivos (DE MARCO, 2015). Tais tumores estão frequentemente associados à hematopoese, trombos de fibrina e vacúolos citoplasmáticos. Há relatos de uma neoplasia adrenocortical em uma glândula e um feocromocitomas na glândula contralateral (HERRTAGE; RAMSEY, 2015; PÉREZ-ALENZA; MELIÁN, 2017).

O HAC iatrogênico é resultante da administração excessiva de glicocorticóides exógenos para tratamentos de distúrbios alérgicos ou imunomediados, o que leva a supressão das concentrações plasmáticas tanto do $\mathrm{CRH}$ hipotalâmico quanto do ACTH hipofisário, causando atrofia adrenal bilateral (DE MARCO, 2015).

Um tipo de HAC para-neoplásico é raramente descrito. Ele está associado a hipercortisolemia secundária à secreção tumoral ectópica de ACTH. O diagnóstico é difícil e se dá por meio de tomografia computorizada e de testes funcionais. Também estão descritos casos raros de HPD com tumor adrenal concomitante e casos de tumores adrenais bilaterais (KOOISTRA; GALAC, 2010; PÉREZ-ALENZA; MELIÁN, 2017).

\section{EPIDEMIOLOGIA}

O HAC é uma das doenças endócrinas mais comumente diagnosticadas no cão e é uma condição rara em gatos. Aparentemente não há predisposição sexual, porém, cadelas são mais suscetíveis ao desenvolvimento tumores adrenais que os machos (HERRTAGE; RAMSEY, 2015). Cães de quaisquer raças podem ser acometidos, porém, as mais acometidas são Poodles, Terriers, Beagles, Dachshunds e Pastores Alemães (ETTINGER; FELDMAN, 2004; PETERSON; KINTZER, 2008; DE MARCO, 2015).

Pöppl et al., (2016) realizaram um estudo epidemiológico com 1400 cães e gatos, acerca das principais endocrinopatias diagnosticadas entre os anos de $2004 \mathrm{e}$ 2014 no Sul do Brasil. Os autores constataram que a principal endocrinopatia que acomete os cães é o HAC, sendo esta responsável por $37 \%$ da casuística, seguida pela diabetes mellitus que é responsável por $22 \%$. A média de idade variou de 9,11 $\pm 3,43$ anos, e $69 \%$ dos pacientes com HAC eram fêmeas. Com relação aos felinos, - HAC foi responsável por apenas 3\% da casuística de endocrinopatias.

O HAC de ocorrência natural pode ser decorrente de tumor hipofisário em cerca de $85 \%$ dos casos, sendo a alteração mais comum observada em cães com HAC com menos de $20 \mathrm{~kg}$ e na faixa etária de dois a 16 anos, com média de sete a nove anos. Na maioria das vezes o tumor hipofisário é considerado um microadenoma, com tamanhos menores que $10 \mathrm{~mm}$, frequentemente menores que 3 $\mathrm{mm}$. Contudo uma proporção de 10 a $50 \%$ dos casos pode apresentar macroadenomas, tumores de hipófise com mais de $10 \mathrm{~mm}$ (PÖPPL, 2009; HERRTAGE; RAMSEY, 2015; DE MARCO, 2015).

Outra possibilidade, presente em cerca de $15 \%$ dos casos de HAC de ocorrência natural, é o HAD, mais comumente diagnosticado em animais com mais de $20 \mathrm{~kg}$, na faixa etária média de 11 a 12 anos. A ocorrência simultânea de HPD e HAD, apesar de um achado raro, também é possível (PÖPPL, 2009). 


\section{SINAIS CLÍNICOS}

O HAC tem início insidioso com progressão lenta e muitas vezes os proprietários consideram os sinais clínicos como parte do processo de envelhecimento normal do cão. Em alguns casos os sinais clínicos podem ser intermitentes com períodos de remissão e recidiva (HERRTAGE; RAMSEY, 2015).

Atualmente os cães são avaliados em estágios muito iniciais de desenvolvimento da doença e, consequentemente, as manifestações clínicas e laboratoriais são mais sutis (BEHREND et al., 2013).

Clinicamente, os animais com HAC desenvolvem uma série de sinais clínicos característicos como a polidipsia (ingestão de água $>100 \mathrm{~mL} / \mathrm{kg}$ de peso corporal/dia) e poliúria (produção de urina $>50 \mathrm{~mL} / \mathrm{kg}$ de peso corporal/dia). A polidipsia é secundária à poliúria e está por sua vez não está muito bem esclarecida, mas tem sido atribuída ao aumento da taxa de filtração glomerular, inibição da liberação de hormônio antidiurético $(A D H)$, inibição da ação do $A D H$ sobre os túbulos renais ou possivelmente a inativação do $A D H$. Ainda pode haver noctúria e incontinência urinária (PÖPPL, 2009; HERRTAGE; RAMSEY, 2015).

Outro sinal clínico comum é a distensão abdominal, caracterizada pelo abaulamento abdominal que assume a aparência de "tonel". Tal aspecto se deve à redistribuição da gordura no abdômen, à hepatomegalia e à fraqueza/atrofia dos músculos abdominais. Também são relatadas letargia e intolerância ao exercício em decorrência da atrofia muscular causada pelo catabolismo proteico, que culmina em diminuição da massa muscular em torno dos membros, no dorso e na região temporal (PETERSON; KINTZER, 2008). Em alguns casos de fraqueza muscular mais grave, o animal pode desenvolver lesões por decúbito prolongado. O HAC pode ainda, mascarar os sinais de doenças articulares crônicas degenerativas em virtude da inibição da inflamação, atrasando o tratamento e assim agravando o problema articular (FELDMAN et al., 2015).

Também são descritos polifagia, taquipneia pelo aumento de deposição de gordura sobre o tórax e pela atrofia e fraqueza muscular, ofego, exoftalmia, úlcera gástrica devido ao aumento da secreção de ácido clorídrico, pancreatite gerada pelo aumento da produção de enzimas gástricas e insulina, miotonia com andar rígido e marcha forçada mais pronunciada em membros pélvicos, anestro persistente e atrofia testicular em razão do efeito feedback negativo das altas concentrações de cortisol sobre a hipófise e supressão da secreção de hormônios gonadotróficos (PÖPPL, 2009; DE MARCO; 2015; NELSON, 2015).

Embora incomuns, sinais neurológicos como demência, depressão, desorientação, perda dos comandos já aprendidos, anorexia, andar compulsivo e desorientado, pressionar a cabeça contra objetos, andar em círculos, ataxia, cegueira, anisocoria e convulsões podem estar presentes no HPD, geralmente no início do tratamento com trilostano ou mitotano devido a remoção do feedback negativo sobre a hipófise e o hipotálamo, permitindo que os tumores hipofisários alarguem rapidamente, causando edema e aumento da pressão intracraniana (PIC) (BEHREND; MELIAN, 2013; HERRTAGE; RAMSEY, 2015).

Hipertensão arterial sistêmica é relatada em alguns casos, com mecanismos pouco esclarecidos. Tal alteração pode induzir à cegueira devido a hemorragias intraoculares e deslocamento da retina. Comprometimentos cardíacos também foram descritos, como a hipertrofia ventricular esquerda e a insuficiência cardíaca congestiva. Sugere-se que tais complicações sejam causadas pela secreção 
excessiva de renina, pela ativação do sistema renina-angiotensina, pela redução da sensibilidade vascular às catecolaminas e redução das prostaglandinas vasodilatadoras (PETERSON; KINTZER, 2008; HERRTAGE; RAMSEY, 2015).

Alterações dermatológicas usualmente estão presentes, como pele fina e elástica, especialmente ao longo do abdômen ventral devido à inibição das mitoses celulares do tecido epidérmico, da multiplicação e migração dos fibroblastos e da atrofia do colágeno. A pele fina juntamente com a distensão abdominal permite a visualização da vasculatura subcutânea, sendo denominada de telangiectasia (DE MARCO, 2016). Pode haver aparecimento de equimoses e estriações devido à atrofia do colágeno em decorrência do catabolismo proteico e também pela maior fragilidade dos vasos sanguíneos causada pelos glicocorticóides (HERRTAGE; RAMSEY, 2015).

Relata-se calcinose cutânea principalmente no pescoço, axilas, abdôme ventral e área inguinal, que está relacionada com o rearranjo da estrutura molecular de proteínas, como o colágeno e a elastina, e na formação de uma matriz orgânica que atrai e liga o cálcio (MILLER et al., 2013; FELDMAN et al., 2015; HERRTAGE; RAMSEY, 2015).

A seborreia é observada em cerca de $33 \%$ dos animais e ocorre secundariamente à atrofia das glândulas sebáceas (ETTINGER; FELDMAN, 2004). Portanto pode ser observada descamação excessiva; comedões causados por "plugs" foliculares (BEHREND; MELIAN, 2013; MILLER et al., 2013). Ocorre ainda o adelgaçamento do pelo levando à alopecia bilateral simétrica não pruriginosa, que inicialmente manifesta-se nos flancos, abdômen, tórax ventral, períneo, pescoço preservando, geralmente a região da cabeça e as extremidades em virtude da localização dos receptores de glicocorticoides (DE MARCO, 2016). Essa alteração ocorre devido ao efeito inibitório do cortisol na fase anágena de crescimento do pelo. Os pelos remanescentes são secos e opacos pois estão na fase telógena ou de repouso do ciclo (ETTINGER; FELDMAN, 2004; HERRTAGE; RAMSEY, 2015).

O prurido é incomum devido aos altos níveis de cortisol circulantes e suas propriedades antipruriginosas, no entanto, ele pode ocorrer em casos de infecções secundárias como piodermite, dermatofitose e demodiciose, causadas pela imunossupressão (ETTINGER; FELDMAN, 2004; PÖPPL, 2009; DE MARCO, 2015; DE MARCO, 2016).

Os cães afetados por HAC durante o primeiro ano de vida apresentam, geralmente, crescimento diminuído, além dos sinais mais frequentemente associados à doença (BEHREND, 2015).

São descritas complicações pulmonares, como mineralização pulmonar intersticial, doença pulmonar intersticial e, raramente, tromboembolismo, no qual há presença de hiperpneia que progride para dispneia. Este último pode estar relacionado à perda glomerular de proteínas, o que resulta na diminuição das concentrações de antitrombina III. Há relatos de doença renal crônica devido à lesão glomerular por hipercortisolemia crônica e também o comprometimento do glomérulo devido a hipertensão arterial sistêmica (ETTINGER; FELDMAN, 2004; HERRTAGE; RAMSEY, 2015).

\section{DIAGNÓSTICO}

A suspeita de hiperadrenocorticismo canino fundamenta-se, inicialmente, em anamnese detalhada e exame físico completo, com reconhecimento de sintomas clínicos e das alterações físicas sugestivas de hipercortisolismo. Os sinais são inespecíficos, contudo destacam-se poliúria, polidipsia, polifagia e alterações 
dermatológicas (PETERSON; KINTZER, 2008; DE MARCO, 2015).

A investigação laboratorial inicial para o diagnóstico do HAC deve compreender hemograma, urinálise, glicemia, dosagem sérica de colesterol, triglicerídios, alanina aminotransferase (ALT), fosfatase alcalina (FA). Soma-se à investigação a ultrassonografia abdominal para a pesquisa de adrenomegalia uni ou bilateral. Os testes hormonais são empregados na sequência para dar suporte ao diagnóstico presuntivo de HAC preestabelecido (DE MARCO, 2015).

\section{Achados Laboratoriais}

No hemograma do cão comumente é encontrado o leucograma de estresse, que corresponde à neutrofilia e monocitose devido ao aumento da liberação destas células da medula óssea para os vasos sanguíneos e à diminuição da sua migração para os tecidos (diapedese); linfopenia relativa e absoluta $(<1,5 \times 109 \mathrm{~L})$ por lise dos linfócitos (linfocitólise) devido a ação tóxica nas membranas ou da sua redistribuição pelos compartimentos linfóides não vasculares (linfonodos, baço) e a eosinopenia $(<0,2 \times 109 \mathrm{~L})$, pelo sequestro de eosinófilos pela medula óssea. Devido ao efeito estimulador dos glicocorticóides sobre a medula óssea, pode ocorrer uma leve policitemia apesar de geralmente a contagem dos glóbulos vermelhos ser normal. Isso ocorre principalmente devido à presença de hipóxia que é secundária a uma diminuição da ventilação. Também pode ser observada trombocitose (FELDMAN et al., 2015; HERRTAGE; RAMSEY, 2015).

Na bioquímica sérica a principal alteração é o aumento das concentrações de FA (>254 UI/L), que podem chegar de cinco a 40 vezes o valor superior de normalidade. Isso ocorre porque os glicocorticóides causam necrose hepatocelular, acúmulo de glicogênio e interferência no fluxo sanguíneo hepático. Um valor normal de FA não exclui HAC e o esse valor aumentado pode ocorrer também em uma variedade de outras condições. $O$ acúmulo de glicogênio nos hepatócitos pode também levar ao aumento discreto da ALT (KOOISTRA; GALAC, 2010).

Outra alteração comum é a hiperglicemia, que ocorre devido ao antagonismo à ação da insulina e à gliconeogênese promovida pelo excesso de glicocorticóides. Cerca de $10 \%$ dos cães com HAC desenvolvem diabetes mellitus, isso porque inicialmente as concentrações de insulina aumentam para manter a normoglicemia, mas depois as ilhotas pancreáticas se esgotam e as células beta são destruídas. Cerca de $90 \%$ dos pacientes têm aumento da concentração plasmática de colesterol (>8mmol/L) em razão do estímulo da lipólise pelos glicocorticóides (HERRTAGE; RAMSEY, 2015). Os triglicérides também podem estar aumentados, embora seja um achado menos comum que o aumento do colesterol. A determinação deste é importante pois a lipemia pode interferir na avaliação precisa de vários parâmetros laboratoriais. Contudo, esses parâmetros são inespecíficos, podendo ocorrer em outras doenças que são diagnósticos diferenciais. Geralmente, os valores de ureia e creatinina estarão reduzidos em decorrência da diurese e da redução da permeabilidade tubular. (HERRTAGE; RAMSEY, 2015).

$\mathrm{Na}$ urinálise, a densidade urinária geralmente é $<1015$, e com frequência observa-se hipostenúria $(<1,008)$, desde que não haja privação de água. Comumente encontra-se glicosúria, principalmente nos casos onde há diabetes mellitus concomitante. Também pode haver proteinúria (relação proteína: creatinina >1) devido a glomerulopatias, hipertensão sistêmica ou infecção do trato urinário inferior (ITUI). Cerca de $50 \%$ dos casos de HAC apresentam ITUI como complicação 
em decorrência da retenção de urina por longo período devido à fraqueza muscular. A presença de células inflamatórias e sedimento pode ser mascarada pelo efeito anti-inflamatório dos glicocorticóides. Pode haver ainda, ascensão da urina para os rins, ocasionando uma pielonefrite. Recomenda-se, portanto, a realização de urocultura e antibiograma a partir da urina obtida por cistocentese, independentemente das alterações observadas na urinálise (HERRTAGE; RAMSEY, 2015; NELSON, 2015).

\section{Exames de Imagem}

O diagnóstico por imagem tem auxiliado os clínicos a identificarem a causa de HAC espontâneo e a extensão da patologia subjacente. No entanto, a localização de uma massa hipofisária ou suprarrenal não indica necessariamente a presença de um tumor funcional. Logo a imagem deve ser interpretada em conjunto com os sinais clínicos e achados laboratoriais (HERRTAGE; RAMSEY, 2015).

$\mathrm{Na}$ radiografia abdominal, os achados mais frequentes são o aumento do contraste abdominal, hepatomegalia discreta à grave, com os lobos ventrais variando de arredondados à acentuadamente achatados e aumento da bexiga, que pode estar distendida mesmo após a micção. Também pode haver presença de cálculos císticos, geralmente associados com ITUI. A radiografia abdominal pode, ainda, revelar a presença de mineralização na região das glândulas adrenais, sugerindo uma neoplasia adrenal, uma vez que em condições normais essas glândulas não são visíveis em radiografias, porém, tumores $<20 \mathrm{~mm}$ de diâmetro não podem ser observados (BEHREND; KEMPPAINEN, 2001; HERRTAGE; RAMSEY, 2015). Cerca de $50 \%$ dos carcinomas da glândula adrenal são calcificados, mas a calcificação não permite fazer a diferenciação entre este e os adenomas (HERRTAGE; RAMSEY, 2015).

Ocasionalmente, verifica-se mineralização da pele, de vasos sanguíneos abdominais, da pelve renal, do fígado, da mucosa gástrica e da aorta abdominal; osteoporose das vértebras; sinais de tromboembolismo pulmonar e efusão pleural. Porém, esses sinais são inespecíficos, podendo ocorrer também na diabetes mellitus e no hipotireoidismo (ETTINGER; FELDMAN, 2004; NELSON, 2015).

No tórax, pode haver mineralização da traqueia e da parede brônquica, achado comum também em cães idosos. A radiografia torácica pode ainda revelar importantes complicações que podem alterar o prognóstico, como a presença de metástase no pulmão de um carcinoma adrenocortical, ICC e tromboembolismo pulmonar (HERRTAGE; RAMSEY, 2015).

A ultrassonografia abdominal ou ecografia é utilizada para avaliar o tamanho, a forma e a eco-estrutura das glândulas adrenais, objetivando determinar a origem do HAC (NELSON, 2015). Fatores como adrenais de pequeno tamanho, conformação torácica profunda, obesidade, órgãos com grandes quantidades de gás, falta de cooperação do animal e animal de grande porte pode dificultar a visualização destas estruturas (NYLAND et al., 2005).

Os rins são utilizados como ponto de referência, sendo que o rim direito é mais difícil de encontrar devido à proximidade com o lobo caudal do fígado, especialmente em animais emaciados nos quais não existe contraste com a gordura abdominal (NELSON, 2015). A glândula adrenal direita está localizada craniomedial ao rim direito, entre o polo caudal do rim e a veia cava caudal, e por estar mais profunda e cranial sob as costelas, é mais difícil de ser localizada. Já a glândula 
adrenal esquerda encontra-se craniomedial ao polo cranial do rim esquerdo, ventrolateral à artéria aorta, entre a origem das artérias mesentérica cranial e renal esquerda, adjacente à primeira ou segunda vértebra lombar (NYLAND et al., 2005; HERRTAGE; RAMSEY, 2015).

Segundo Herrtage e Ramsey (2015), a glândula adrenal tem normalmente formato achatado, é bilobada e hipoecóica em relação aos tecidos circundantes. O lobo cranial tem formato de espátula e é maior, enquanto o esquerdo espreita-se distalmente. A região medular é mais hiperecóica quando comparada à cortical. As dimensões máximas são de 10 a $52 \mathrm{~mm} \times 2$ a $12 \mathrm{~mm}$, variando de acordo com o tamanho e idade dos animais.

A simetria é considerada fator crucial para a distinção etiológica do HAC. No HAD há formação adrenal unilateral e atrofia da adrenal contralateral, esta última devido à supressão crônica da secreção de ACTH hipofisário. Tumores adrenais bilaterais são raros. Já no HPD, as glândulas adrenais são simetricamente aumentadas, com bordos lisos e regulares. Há relatos de HPD concomitante à tumores adrenais e alguns animais com HAC apresentam medições das glândulas adrenais dentro dos parâmetros normais (PETERSON, 2007; BEHREND, 2015). Os aumentos de espessura não são específicos o suficiente para diagnosticar o HAC, pois há considerável sobreposição entre as mensurações da adrenal normal e da hiperplásica. No entanto cães com teste positivo para HAC e com as glândulas simétricas na ultrassonografia são positivos para HPD (HERRTAGE; RAMSEY, 2015).

Os tumores variam de aparência, podendo ser hipoecogênicos, isoecogênicos ou hiperecogênicos quando comparados com o córtex renal, ou ainda heterogêneos, apresentando mineralização ou zonas de necrose (BEHREND; KEMPPAINEN, 2001). São exemplos os adenomas, os feocromocitomas, que raramente apresentam mineralização, tumores que formaram metástases na glândula adrenal e os carcinomas, que podem invadir tecidos, vasos sanguíneos e comprimir órgãos adjacentes, fazendo necessário assim, o uso do doppler para verificar se houve compressão da veia cava caudal (BEHREND; KEMPPAINEN, 2001; NYLAND et al., 2005; NELSON, 2015). Não é possível avaliar o tipo de neoplasia apenas avaliando as glândulas adrenais na ultrassonografia, deve-se procurar sinais de metastização especialmente no fígado, baço e rins (HERRTAGE; RAMSEY, 2015).

Apesar de a ultrassonografia ser a modalidade de imagem preferida para avaliar as glândulas adrenais em Medicina Veterinária, nem sempre ela é esclarecedora, como nos casos de hiperplasia assimétrica além de não permitir a avaliação do tipo de neoplasia. Assim, ressalta-se a importância dos sinais clínicos e a realização de testes endócrinos para uma completa interpretação dos resultados dos exames de imagem (SOULSBY et al., 2015).

Outros exames de imagem incluem a tomografia computorizada (TC) e a ressonância magnética $(\mathrm{RM})$, que servem para avaliar o tamanho e simetria das glândulas adrenais bem como determinar a presença de um macroadenoma ou macroadenocarcinoma de hipófise (NELSON, 2015).

A TC com contraste (iodado ou gadolínio) é mais sensível que a ultrassonografia quando se pretende avaliar a estrutura das glândulas adrenais. $\mathrm{Na}$ hipófise o líquido de contraste passa livremente da circulação sanguínea para o interstício, permitindo determinar com exatidão as dimensões de um tumor, identificar se há edema peritumoral, identificar as estruturas neurais adjacentes, 
como por exemplo, se há invasão da veia cava caudal pelo tumor e aderências entre a glândula adrenal e a veia cava caudal e ainda diferenciar hiperplasia bilateral de unilateral. Porém, nem sempre é possível detectar aumento de tamanho das glândulas adrenais, diferenciar hiperplasia nodular unilateral de um tumor adrenal ou diferenciar neoplasias malignas de benignas. Alguns tumores pequenos podem passar despercebidos e, como tal, a ausência de uma massa visível não implica que o animal não tenha HPD (BEHREND, 2015; HERRTAGE; RAMSEY, 2015; NELSON, 2015).

A RM é mais sensível que a TC na detecção de microadenomas hipofisários (até $3 \mathrm{~mm}$ ) e na localização de alterações como edema, necrose, cistos ou hemorragias devido à melhor imagem obtida das glândulas adrenais, pois esta não é afetada pela barreira óssea, (DE MARCO, 2015; NELSON, 2015). Estudos revelaram que cerca de $50 \%$ dos cães com HPD apresentam massa detectável na hipófise quando realizada a RM (BERTOY et al., 1996, citado por HERRTAGE; RAMSEY, 2015).

Nos casos com sintomas neurológicos, a RM ou a TC cerebral são essenciais para o planejamento cirúrgico de uma possível adrenalectomia. Porém, esses exames são dispendiosos, têm baixa disponibilidade, requerem anestesia que pode durar até 2 horas e técnicos com experiência na interpretação dos resultados obtidos e por isso nem sempre são técnicas acessíveis (BEHREND, 2015).

\section{Testes de Função Endócrina}

O diagnóstico definitivo de HAC é efetuado em duas etapas: a confirmação da hipótese e a detecção da sua causa. Em ambas as fases, os testes funcionais desempenham um papel relevante, permitindo diferenciar HAC hipófise-dependente de tumores adrenais, planejar o tratamento mais adequado e determinar um prognóstico mais preciso. Entretanto, nenhum teste diagnóstico é infalível, podendo apresentar resultado falso-positivo em cães com doenças não-endócrinas, ou falsonegativo. Animais com insuficiência renal ou hepática crônica, diabetes mellitus não controlado, podem apresentar valores alterados nos testes funcionais endócrinos (BEHREND, 2015; DE MARCO, 2015; HERRTAGE; RAMSEY, 2015).

A preferência de Herrtage e Ramsey (2015), é pelo emprego o teste de estimulação com ACTH (TeACTH) como primeiro teste de triagem, e do teste de supressão com dexametasona em doses baixas (TSDDB) se o TeACTH fornecer um resultado no intervalo de referência em um cão com sinais clínicos suspeitos de hiperadrenocorticismo.

Caso se obtenha um resultado negativo em mais de um teste, deve-se considerar a ausência de HAC ou a presença de uma forma leve da doença. Neste último caso, o animal deve ser testado novamente após três a seis meses se houver a progressão da doença (BEHREND et al., 2013).

É importante ressaltar que a dosagem de cortisol basal não é um teste recomendado, pois não traz informações confiáveis sobre a função adrenocortical, uma vez que, o valor de cortisol varia ao longo do dia. Animais saudáveis podem apresentar concentrações elevadas de cortisol, assim como pacientes com HPD ou HAD podem apresentar valores basais $(0,5$ a $6 \mathrm{mg} / \mathrm{dL})$ durante a maior parte do dia (PÖPPL, 2009; HERRTAGE; RAMSEY, 2015; NELSON, 2015).

\section{Teste de Estimulação com ACTH}


É o teste de eleição numa abordagem inicial do HAC por ser simples, rápido e confiável se for realizado antes do início do tratamento, com sensibilidade de aproximadamente $80 \%$ e especificidade de $85 \%$ a $90 \%$. É a melhor opção para distinguir o HAC iatrogênico do espontâneo, onde ele identifica $>50 \%$ dos cães com HAD e cerca de $85 \%$ dos cães com HPD. No entanto, tem como inconveniente a incapacidade para estabelecer um diagnóstico etiológico, ou seja, não distingue HAD de HPD. Em casos de diabetes mellitus e de piometra, por exemplo, o animal sob estresse crônico pode desenvolver algum grau de hiperplasia adrenal, levando à obtenção de um falso-positivo. Resultados falsos-negativos podem ocorrer em estágios iniciais da doença, quando a hiperplasia adrenal é mínima, ou quando o tumor adrenal não tem receptores da corticotropina (NELSON, 2015; PÉREZALENZA; MELIÁN, 2017).

O TeACTH baseia-se na capacidade de resposta das adrenais, a qual está relacionada com o tamanho e atividade das mesmas. O ACTH em dose forte estimulará a secreção de cortisol endógeno pelas adrenais. Assim, nos casos de hipertrofia destas glândulas, a resposta ao teste é superior a fisiológica (PETERSON, 2007; DE MARCO, 2015).

O procedimento consiste em coletar uma amostra de sangue para mensuração do cortisol basal; injetar $250 \mathrm{~g}$ de ACTH sintético (tetracosactida, cosintropina) por via intravenosa ou intramuscular em cães com $>5 \mathrm{~kg}, 125 \mathrm{~g} \mathrm{em}$ cães com $<5 \mathrm{~kg}$, ou alternativamente $5 \mathrm{mg} / \mathrm{kg}$ e coletar uma segunda amostra 60 minutos depois para mensurar o cortisol novamente. Se após esses 60 minutos a concentração de cortisol for maior que $22 \mathrm{mg} / \mathrm{dL}$ em um paciente não estressado e sem doenças graves concomitantes, o resultado é positivo para HAC espontâneo. Uma resposta fraca na mensuração do cortisol ( $<6 \mathrm{mg} / \mathrm{dL}$ ) se este mantiver o valor basal (inferior a $5 \mathrm{~g} / \mathrm{dl}$ ) conclui-se que se trata de HAC iatrogênico ou hipoadrenocorticismo. Essa diferenciação é feita com base no histórico de uso de corticóides e a presença de sinais clínicos de HAC, que condizem com HAC iatrogênico (PÖPPL, 2009; HERRTAGE; RAMSEY, 2015; PÉREZ-ALENZA; MELIÁN, 2017).

Um estudo realizado por Martins e Jericó (2017) demonstrou a eficácia da realização do TeACTH com a dose de $1 \mathrm{~g} / \mathrm{kg}$, uma vez que esta dosagem promoveu o mesmo tipo de variação nos valores de cortisol que a dosagem de $5 \mathrm{~g} / \mathrm{kg}$, tradicionalmente utilizada na rotina. Desta forma, os custos com a realização do TeACTH, tanto para diagnóstico inicial do HAC quanto para monitoramento da terapia, podem ser reduzidos, proporcionando maior aplicabilidade do teste.

Em casos onde o animal está passando por terapia com glicocorticóides como a hidrocortisona, a prednisona e a prednisolona, é necessário que estes sejam suspendidos 24 horas antes da realização do teste para que não haja reação cruzada. A dexametasona não apresenta reação cruzada, mas ocasionará a supressão do cortisol em doentes com funcionamento normal do eixo hipotálamohipófise-adrenal. Quando o cão apresentar diabetes mellitus, o teste deverá ser realizado apenas após o início da insulinoterapia (HERRTAGE; RAMSEY, 2015).

\section{Teste de Supressão com Dexametasona em Doses Baixas}

O TSDDB é considerado o teste de escolha para o diagnóstico definitivo de HAC espontâneo, pois sua sensibilidade varia de 85 a 100\% (DE MARCO, 2015; 
PÉREZ-ALENZA; MELIÁN, 2017). A especificidade, no entanto, varia de 40 a $50 \%$ e é afetada pela presença de doenças não-adrenais concomitantes, uso de anticonvulsivantes, glicocorticóides exógenos, e pelo estresse (PÉREZ-ALENZA; MELIÁN, 2017). Dentre as desvantagens deste teste estão a demora de 8 horas para ser concluído, a não diferenciação da etiologia da doença, a baixa acurácia para o HAC iatrogênico e o não fornecimento de informação que possa ser usada para a monitoração do tratamento (HERRTAGE; RAMSEY, 2015; PÉREZ-ALENZA; MELIÁN, 2017).

O teste baseia-se na administração de um glicocorticóide, a dexametasona, por esta não apresentar reação cruzada com o cortisol endógeno do paciente no radioimunoensaio, e consequente avaliação da sensibilidade do eixo hipotálamohipofisário ao efeito supressor desta, que é 30 vezes superior ao do cortisol (DE MARCO, NELSON, 2015).

Para a realização do teste, o paciente deve estar livre de cortisona exógena por pelo menos 60 dias. Após a dosagem de cortisol sérico é administrado ao paciente o fosfato de dexametasona ou dexametasona em polietilenoglicol na dose de 0,01 e $0,015 \mathrm{mg} / \mathrm{kg}$ respetivamente, por via intravenosa ou intramuscular. A concentração plasmática de cortisol deve ser avaliada novamente 4 e 8 horas após a administração de dexametasona (BEHREND, 2015; NELSON, 2015).

Em um cão saudável, após duas a três horas da administração de dexametasona haverá inibição da secreção de ACTH pela hipófise, provocando uma diminuição da concentração de cortisol circulante por mais de 24 horas. Assim quando este for mensurado geralmente estará inferior a $40 \mathrm{nmol} / \mathrm{L}$. Após oito horas, se a quantidade de dexametasona não for suficiente para suprimir as concentrações de cortisol circulante para menos de $40 \mathrm{nmol} / \mathrm{L}$, o diagnóstico de HAC está confirmado. Deve-se em seguida avaliar o valor de cortisol plasmático mensurado após quatro horas, pois, doses baixas de dexametasona suprimem a secreção da ACTH durante duas a seis horas após a administração em $60 \%$ dos cães com HPD, o que não acontece nos animais com HAD. Assim, quando existe supressão às quatro horas, mas não às oito horas, o diagnóstico de HPD pode ser feito (BEHREND, 2015; NELSON, 2015).

No HPD, a hipófise é resistente ao feedbacknegativo da dexametasona e continua a secretar ACTH após oito horas e, consequentemente, há produção de cortisol pelas glândulas adrenais. Nos cães com tumores adrenais, a secreção de cortisol não depende das concentrações de ACTH, portanto, a dexametasona não afeta a concentração plasmática de cortisol. Valores entre 30 e $40 \mathrm{nmol} / \mathrm{L}$ não excluem nem confirmam o diagnóstico. Quando o valor anterior à administração de dexametasona é inferior a $30 \mathrm{nmol} / \mathrm{L}$ não é possível tirar conclusões (BEHREND; KEMPPAINEN, 2001; NELSON, 2015). A incapacidade para suprimir o cortisol plasmático em quatro e oito horas não é útil para determinar a etiologia do HAC (HERRTAGE; RAMSEY, 2015).

\section{Relação Cortisol: Creatinina Urinária}

Trata-se de um teste prático de triagem, com sensibilidade de 85 a $95 \%$, onde a obtenção de um valor normal exclui definitivamente o diagnóstico de HAC, entretanto, o resultado positivo deve ser confirmado com o TeACTH ou o TSDDB. As desvantagens incluem a especificidade baixa (20 a $30 \%)$, ter pouco valor no acompanhamento da resposta ao tratamento com mitotano e a interferência de variáveis na acurácia do teste, como estresse, hipertermia e doenças crônicas tais 
como a insuficiência renal e hepática (PETERSON, 2007; PETERSON; KINTZER, 2008; NELSON, 2015).

A coleta da urina para realização do teste deve ser feita durante a manhã, uma vez que esta reflete a excreção urinária de toda a noite, conferindo uma correta aproximação da dosagem de cortisol em 24 horas (PETERSON; KINTZER, 2008). Recomenda-se também que a coleta seja feita pelo proprietário em casa para que o animal não se estresse, evitando alterações nas concentrações de cortisol na urina. Assim, a urina deve ser colhida por cinco dias consecutivos e na mesma hora. As amostras devem colocadas num tubo seco com antisséptico e refrigeradas a $4^{\circ} \mathrm{C}$ ou enviadas imediatamente para o laboratório (DE MARCO, 2015; NELSON, 2015).

A excreção urinária de cortisol varia de acordo com a sua concentração sanguínea e a quantidade de urina filtrada. Para diminuir esse fator de diluição, foi proposta a medição concomitante da creatinina urinária, pois esta tem excreção relativamente constante quando a função renal é estável, conseguindo-se assim, interpretar a concentração de cortisol independentemente do volume de urina produzida (BEHREND; KEMPPAINEN, 2001). Portanto, RCCU = Cortisol Urinário (qmol/L) / Creatinina Urinária (qmol/L) x 10-6. Um resultado <10 x 10-6 exclui o HAC; um resultado entre $>10 \times 10-6$ e $<60 \times 10-6$ levanta uma hipótese de HAC porém ainda é duvidoso e um resultado > 60 x 10-6 confirma o HAC. O RCCU não diferencia HAC hipofisário do adrenal, a não ser que ultrapasse $100 \times 10-6$, quando aumenta a probabilidade de ser HPD (HERRTAGE; RAMSEY, 2015).

\section{Concentração Plasmática de ACTH Endógeno}

Este teste é um método preciso na identificação etiológica do HAC e geralmente é utilizado quando os resultados da ultrassonografia abdominal são inconsistentes e inconclusivos (HERRTAGE; RAMSEY, 2015). Entretanto, na experiência de Nelson (2015), este exame é pouco realizado, uma vez que, o ultrassom abdominal e o TSDDB são bastante eficazes na diferenciação de HPD e HAD.

A amostra de sangue deve ser coletada pela manhã, armazenada em um tubo com ácido etileno diaminotetracetico (EDTA) e centrifugada rapidamente, pois o ACTH é uma molécula muito instável, de degradação fácil, com uma meia-vida de apenas alguns minutos e que pode ser adsorvida pelas paredes de vidro do tubo. Após a centrifugação o plasma deve ser congelado imediatamente e enviado para análise laboratorial envolto por gelo. Com o objetivo de inibir a degradação de ACTH, é comum adicionar a aprotinina, que é um inibidor das proteases sanguíneas. A dosagem deve ser realizada por quimioluminescência (DE MARCO, 2015).

Em cães saudáveis as concentrações de ACTH endógeno variam de 2,91 a $11 \mathrm{pmol} / \mathrm{L}$. Nos casos de HPD é esperado um valor border line ou aumentado ( 6 $\mathrm{pmol} / \mathrm{L})$ secundário a hiperplasia ou tumor hipofisário. Já valores séricos baixos ( $1.1 \mathrm{pmol} / \mathrm{L}$ ) são esperados em cães com HAD pois o cortisol é produzido pelo tecido tumoral de forma autônoma à estimulação do ACTH e as células hipofisárias são sensíveis ao feedback negativo induzido pelo cortisol em excesso (HERRTAGE; RAMSEY, 2015).

\section{Diagnósticos Diferenciais}

O diagnóstico diferencial é essencial para se confirmar o $\mathrm{HAC}$ e fundamental 
para um tratamento adequado e consequentemente com melhor prognóstico (PETERSON; KINTZER, 2008; NELSON, 2015). Sinais clínicos como a proteinúria, podem ocorrer também no hipotireoidismo, na diabetes mellitus, na doença hepática colestática e na nefropatia. A hiperglicemia é um achado típico da diabetes mellitus, assim como a poliúria e polidipsia, que por sua vez, podem ocorrer também na doença renal, na hipercalcemia, na acromegalia e em uma possível terapia anticonvulsivante por exemplo (FELDMAN et al., 2015; HERRTAGE; RAMSEY, 2015).

Os diagnósticos diferenciais mais importantes, portanto, são a diabetes mellitus, a acromegalia, a diabetes insipidus, insuficiência renal e hepática, pielonefrite, hipotireoidismo, hipertireoidismo, sertolioma e hipercalcemia (FELDMAN et al., 2015; PETERSON; KINTZER, 2008).

Apesar de muitas vezes os sinais clínicos serem inespecíficos na maioria dos cães com HAC, quando combinados e associados com os achados laboratoriais, o diagnóstico presuntivo pode ser levantado. A realização do teste TeACTH como triagem reforça esta hipótese e descarta as demais doenças diferenciais (FELDMAN et al., 2015; HERRTAGE; RAMSEY, 2015).

\section{TRATAMENTO}

Atualmente existem várias opções terapêuticas para o HAC. Para selecionar o tratamento adequado para cada paciente deve-se considerar o estado geral do animal, as características da opção terapêutica, o tipo de HAC e a colaboração e disponibilidade financeira do proprietário. Independentemente do método de tratamento selecionado, todos possuem efeitos colaterais, a maior parte é dispendiosa, requerem uma monitoração periódica e adesão dos proprietários para obter uma resposta satisfatória (DE MARCO, 2015; NELSON, 2015).

\section{Trilostano}

\section{TRATAMENTO MEDICAMENTOSO}

O trilostano é um análogo esteroide sintético sem atividade hormonal, que atua como inibidor competitivo da enzima 3- $\beta$ hidroxiesteroide desidrogenase, impedindo a conversão da pregnenolona em progesterona e, consequentemente, bloqueando a síntese de glicocorticoides, mineralocorticoides e hormônios sexuais. Sua ação tem duração média de 12 horas e a atividade máxima ocorre quatro a seis horas após a sua administração (PETERSON; KINTZER, 2008; NELSON, 2015).

Este composto é utilizado como a modalidade terapêutica primária para o HPD em cães, pois é eficiente no controle dos sinais clínicos em $80 \%$ dos casos. Também é uma alternativa em cães em que mitotano é ineficaz ou não pode ser usado devido a problemas de sensibilidade e como forma de reverter as alterações metabólicas do HAC antes da adrenalectomia. A manipulação não é recomendada devido a estudos que indicaram variação no teor do trilostano em algumas cápsulas (NELSON, 2015).

O medicamento disponível no mercado é o Vetoryl ${ }^{\circledR}$, que existe sob a fórmula de cápsulas de 10,30,60 e $120 \mathrm{mg}$. A dose inicial recomendada pelo fabricante é de 3 a $6 \mathrm{mg} / \mathrm{kg}$, administrado por via oral junto com o alimento, uma vez ao dia (HERRTAGE; RAMSEY, 2015). Entretanto, Nelson (2015), rotineiramente usa a dose de $1 \mathrm{mg} / \mathrm{kg}$ duas vezes ao dia.

Sabe-se que o efeito de supressão do cortisol exercido pelo mitotano dura 
menos de 24 horas, logo, pode haver persistência dos sinais clínicos e subsequente administração de grandes doses de trilostano, o que leva a maior ocorrência de efeitos adversos. Esta intercorrência pode ser evitada quando o medicamento é administrado duas vezes ao dia. (HERRTAGE; RAMSEY, 2015; NELSON, 2015).

A monitoração do animal é de extrema importância. O hemograma, a bioquímica sérica, a mensuração sérica de eletrólitos e o TeACTH devem ser realizados 10 dias após o início do tratamento, com um e três meses e depois a cada três a seis meses. (HERRTAGE; RAMSEY, 2015). Um bom controle é alcançado quando a concentração de cortisol após a administração de ACTH varia de 60 a $145 \mathrm{nmol} / \mathrm{L}$, no entanto, a obtenção da supressão máxima da função adrenocortical pode levar várias semanas (NELSON, 2015).

A dose deve ser ajustada com base na resposta do TeACTH realizado de quatro a seis horas após a administração do trilostano, entretanto, ajustes frequentes na dose devem ser evitados, principalmente quando as concentrações de cortisol após a administração de ACTH estão entre 145 e 225 nmol/L, o proprietário relatar melhora dos sinais clínicos e o cão parecer estar bem. Da mesma maneira, cães que chegam à concentração de cortisol pós-ACTH entre 60 a 145 logo após o início do tratamento devem ser monitorados quanto ao desenvolvimento de sinais clínicos de hipoadrenocorticismo (HERRTAGE; RAMSEY, 2015; NELSON, 2015).

Os efeitos adversos são menos frequentes, quando comparados aos do mitotano, ocorrendo em 10 a $15 \%$ dos animais e estão relacionados com 0 hipoadrenocorticismo: letargia, vômito, diarreia, depressão e anorexia, porém, na maioria das vezes são leves e autolimitantes, podendo ser corrigidos com a suspensão ( 3 a $4 \%$ dos casos) ou ajuste da dose. Também foram relatados: aumento das concentrações séricas de sódio e potássio e redução da relação entre eles (PETERSON; KINTZER, 2008).

Dentre as complicações estão descritos dois casos de morte súbita ainda não bem esclarecidos, onde há suspeita de relação com insuficiência da válvula mitral e doença crônica valvular, necrose bilateral das adrenais 25 dias após o início do tratamento com dose de $7,1 \mathrm{mg} / \mathrm{kg}$, sintomatologia neurológica em decorrência do rápido crescimento do tumor hipofisário e dois casos de hipoadrenocorticismo agudo (PETERSON; KINTZER, 2008). O desenvolvimento de necrose adrenal, principalmente na zona fasciculada, pode ser decorrente da hipersecreção de ACTH que, juntamente com o aumento de tamanho das glândulas adrenais, pode, também, causar, paradoxalmente, necrose e hemorragia das glândulas adrenais (HERRTAGE; RAMSEY, 2015; PÉREZ-ALENZA; MELIÁN, 2017).

O trilostano não é recomendado para animais com menos de $5 \mathrm{~kg}$. Dentre as contraindicações estão cães com doença hepática e renal, pois este pode interagir com inibidores da enzima conversora de angiotensina (IECA) e com a espironolactona (antagonista da aldosterona) interferindo na síntese de aldosterona, sendo fatores de risco para o desenvolvimento de hipercalcemia. Além disso, é contraindicado para fêmeas gestantes, em lactação ou qualquer animal destinado à reprodução por interferir na síntese de hormônios sexuais. O alto custo do medicamento também é uma limitação para seu uso (HERRTAGE; RAMSEY, 2015).

\section{Mitotano}

O mitotano, ou op'- DDD é um fármaco que possui ação citotóxica através do isômero o'p, provocando necrose seletiva das zonas fasciculada e reticular, 
enquanto tende a preservar a zona glomerulosa do córtex da adrenal. Ele pode ser utilizado nos casos de HPD e também é uma alternativa no HAD quando a adrenalectomia não for possível de ser realizada ou quando houver doença residual após a realização deste procedimento (DE MARCO, 2015; NELSON, 2015).

Antes de se iniciar o tratamento deve-se medir o consumo de água por ao menos dois períodos de 24 horas consecutivos. Caso o apetite e a ingestão de água não estejam aumentados, deve-se efetuar a dosagem do cortisol antes e após o TeACTH, possibilitando assim, a monitoração dos efeitos do tratamento (HERRTAGE; RAMSEY, 2015).

A terapia com mitotano é dividida nas fases de indução, com duração média 10 dias e fase de manutenção. Na fase de indução deve ser administrado por via oral na dose de $50 \mathrm{mg} / \mathrm{kg} /$ dia dividindo-se a dose em duas administrações. Sua absorção é otimizada quando a dose é triturada, misturada com uma pequena quantidade de óleo vegetal e administrada com o alimento. Essa fase inicial segue até que se verifique a redução significativa da ingestão de água e do apetite ou o cão apresente êmese, diarreia e apatia. Então o tratamento de indução é interrompido, realiza-se um TeACTH onde espera-se concentrações de cortisol entre $20 \mathrm{nmol} / \mathrm{L}$ a $120 \mathrm{nmol} / \mathrm{L}$, para ser considerada a eficácia do tratamento e iniciar-se a fase de manutenção. Em cães com polidipsia ou diabetes mellitus associada ao HAC, a dose deve ser reduzida para 25 a 35 mg/kg/dia (HERRTAGE; RAMSEY, 2015; NELSON, 2015).

Caso esses sinais clínicos não apareçam, deve-se realizar um TeACTH após 10 dias do início da terapia, e se as concentrações de cortisol estiverem dentro da faixa esperada, deve-se suspender o tratamento. Cães que não apresentarem poliúria e polifagia devem ser submetidos ao TeACTH a cada cinco dias. Se a concentração sérica de cortisol for indetectável, deve-se esperar o alcance da faixa de normalidade para iniciar a fase de manutenção. Durante esta fase de indução alguns efeitos adversos são descritos, como anorexia, êmese e diarreia, porém raramente são graves. Podem ocorrer ainda alterações neurológicas, que podem estar relacionadas ao crescimento de um macroadenoma, geralmente responsivo à terapia com glicocorticóides (HERRTAGE; RAMSEY, 2015).

$\mathrm{Na}$ fase de manutenção a dose é de $50 \mathrm{mg} / \mathrm{kg} / \mathrm{semana}$ junto com o alimento. Recomenda-se que a administração seja a noite, pois o mitotano pode causar sonolência. Depressão profunda e fraqueza podem exigir um novo TeACTH e uma redução da dose, assim como o não controle da polidipsia pode demandar o aumento da dose. Esta fase é importante pois caso não seja realizada adequadamente, o mitotano provocará uma hiperplasia das zonas fasciculada e reticular e os sinais clínicos reaparecerão. Em 5 a 17\% dos casos pode ocorrer hipoadrenocorticismo primário com insuficiência de glicocorticóides e mineralocorticóides durante esta fase, devendo-se então interromper a terapia e suplementar essas deficiências (HERRTAGE; RAMSEY, 2015).

Para monitorar a eficiência do tratamento deve-se efetuar o TeACTH bem como o perfil bioquímico a cada um a três meses do início da fase de manutenção e posteriormente duas vezes por ano (DE MARCO, 2015). Nesta fase espera-se que haja redução do consumo de água, do apetite e do débito urinário (HERRTAGE; RAMSEY, 2015).

Alguns autores recomendam associar o uso de glicocorticóides durante a fase de indução para minimizar ou evitar as reações adversas causadas pelos hipocortisolismo induzido pelo mitotano, porém, outros autores se opõem ao uso 
pois alegam que sinais clínicos como polidipsia, polifagia e poliúria, que são usados para identificar o controle da doença, podem persistir (NELSON, 2015).

É relatado também outro método de controle do HAC com o mitotano, chamado de adrenalectomia medicamentosa. O objetivo deste tratamento é destruir as zonas fasciculada e reticular, com altas doses de mitotano, de modo a cessar a produção excessiva de cortisol e restringir sua síntese a níveis basais, convertendo assim, o HAC em hipoadrenocorticismo. A dose utilizada é 50 a $75 \mathrm{mg} / \mathrm{kg} / \mathrm{dia}$ durante 25 dias dividida em três ou quatro doses diárias. No terceiro dia do tratamento inicia-se a administração de fludrocortisona $(0,01 \mathrm{mg} / \mathrm{kg}$, uma vez ao dia) e cortisona (1 mg/kg, duas vezes ao dia). Uma semana após o fim do tratamento, a dose de cortisona é diminuída para a metade. Caso haja vômitos, anorexia, diarreia, fraqueza e sintomatologia neurológica o tratamento deve ser interrompido por curtos períodos de tempo (NELSON, 2015). Este protocolo pode ser útil em cães com HAC e diabetes mellitus associada, pois permite uma melhor regulação e monitoração desta última (REINE, 2007).

\section{Fármacos Alternativos}

Existem vários outros fármacos para tratamento médico do HAC, como a bromocriptina, a cabergolina, a ciproheptadina, o ácido retinóico, o cloridrato de selegilina (L-deprenil), a metiropona e a aminoglutetimida, que demonstram baixa eficácia ou ainda não foram pesquisados adequadamente e não são considerados como opções terapêuticas importantes (PETERSON; KINTZER, 2008; BEHREND, 2015; DE MARCO, 2015).

O cetoconazol, um antifúngico derivado imidazólico de amplo espectro, tem sido utilizado com sucesso em torno de 50 a $75 \%$ dos casos. Seu mecanismo de ação é por meio da interação com o sistema enzimático esteroidogênico, interferindo na biossíntese de esteroides e suprimindo a secreção de cortisol. Entretanto, este fármaco induz mais efeitos colaterais que o trilostano e por isso só deve ser utilizado em casos refratários ou intolerância ao mitotano e o trilostano. A dose inicial é de 5 $\mathrm{mg} / \mathrm{kg}$, por via oral, a cada 12 horas, durante sete dias. Caso não ocorra reação adversa, a dose é aumentada para até $10 \mathrm{mg} / \mathrm{kg}$, a cada 12 horas, durante 14 dias, podendo chegar a $20 \mathrm{mg} / \mathrm{kg}$ a cada 12 horas. A eficácia do tratamento é determinada pelo teste de resposta ao ACTH após 15 dias, onde espera-se obter níveis de cortisol pós-ACTH inferiores a $5 \mathrm{~g} / \mathrm{d} \ell$ (DE MARCO, 2015; HERRTAGE; RAMSEY, 2015).

\section{Adrenalectomia}

\section{TRATAMENTO CIRÚRGICO}

Para o tratamento de HAD a primeira opção de escolha é a adrenalectomia (DE MARCO, 2015; NELSON, 2015), sendo principalmente indicada nos casos de tumor unilateral, uma vez que em tumores bilaterais a técnica culminará em HAC iatrogênico e o animal necessitará de suplementação hormonal por toda vida. O cão deve ser estabilizado antes da cirurgia, pois um bom estado geral é fundamental para o sucesso da adrenalectomia. Caso esta estabilização não seja possível, o risco cirúrgico e anestésico aumenta, impossibilitando o procedimento e fazendo necessário, assim, o uso da terapia medicamentosa. Outros casos que inviabilizam a adrenalectomia são a presença de metástase e a compressão de estruturas adjacentes pelo tumor (BEHREND, 2015; NELSON, 2015). 
A técnica é minuciosa e exige experiência do cirurgião (FOSSUM; CAPLAN, 2014). O acesso deve ser realizado por meio de laparotomia na linha média ventral, entretanto, alguns autores defendem a abordagem paracostal, que propicia exposição inapropriada. Uma inspeção dos demais órgaos da cavidade abdominal devem ser inspecionados quanto à presença de metástase (HERRTAGE; RAMSEY, 2015). É realizada, então, a dissecção da periferia da glândula, individualização da veia frênico-abdominal e artéria renal, e exérese da adrenal, idealmente numa só peça, a fim de evitar que pequenos fragmentos de tecido tumoral permaneçam na cavidade abdominal. Devem ser utilizados fios de sutura de reabsorção lenta no encerramento dos planos musculares devido a cicatrização retardada dos animais com HAC (FOSSUM; CAPLAN, 2014).

No transoperatório, devido à súbita condição de hipoadrenocorticismo, pode haver hipoglicemia, hiponatremia, hipercalemia e hipotensão, devendo-se então suplementar com glicocorticóides e mineralocorticóides ainda nesse período (FOSSUM; CAPLAN, 2014). Herrtage e Ramsey (2015), sugerem a administração intravenosa de hidrocortisona (5 a $10 \mathrm{mg} / \mathrm{kg}$, a cada $6 \mathrm{~h}$, ou na forma de infusão contínua na taxa de $0,5 \mathrm{mg} / \mathrm{kg} / \mathrm{h}$ ), dexametasona $(0,1$ a $2,0 \mathrm{mg} / \mathrm{kg}$, por via intravenosa, a cada $6 \mathrm{~h}$ ) ou prenisolona oral com fludrocortisona, conforme necessário. Entretanto, há controvérsia entre diferentes autores e a suplementação é considerada inútil ou facultativa quando a adrenalectomia é unilateral. No pósoperatório desta, a suplementação deverá ser progressivamente diminuída até que a adrenal remanescente volte a sua produção normal (FOSSUM; CAPLAN, 2014).

A complicação pós-operatória mais comum e responsável por altas taxas de mortalidade (20 a 30\%) é o tromboembolismo, tornando necessária a terapia com anticoagulantes (heparina) e trombolíticos (estreptoquinase) e a disponibilidade de instalações de cuidados intensivos (HERRTAGE; RAMSEY, 2015; NELSON, 2015).

\section{Hipofisectomia}

No Brasil, para o tratamento de HAC causado por tumores hipofisários, existem apenas as opções medicamentosas, sendo as principais o trilostano e o mitotano, entretanto na Europa e Estados Unidos, a hipofisectomia é realizada (BEHREND, 2015; DE MARCO, 2015).

A técnica utiliza uma abordagem transesfenoidal e consiste na retirada parcial ou total da hipófise e por ser uma técnica minuciosa, necessita de equipe treinada. Dentre as complicações relatadas, as mais comuns são as hemorragias, visualização e remoção incompleta das lesões maiores e diabetes insípido transitória (50\% dos pacientes), exigindo tratamento e reposição dos hormônios tireoidianos e glicocorticóides por toda vida, hiposomatotropismo, hipotireoidismo e o hipoadrenocorticismo (HERRTAGE; RAMSEY, 2015). Também são relatadas redução transitória ou cessação da produção de lágrimas, hipernatremia e reincidiva meses após a cirurgia, sendo que esta última está relacionada, dentre outros fatores, a alta relação cortisol/creatinina urinária e aumento das concentrações de alfa-MSH antes da cirurgia (PÉREZ-ALENZA; MELIÁN, 2017).

\section{Outras opções terapêuticas}

A radioterapia ou radiação com feixe externo, é uma opção indicada nos casos de HPD onde há um macroadenoma causando sintomatologia neurológica. 
Nesta técnica emprega-se uma megavoltagem de um acelerador linear ou de feixes de cobalto 60 para penetrar profundamente a hipófise permitindo a redução do tumor e limitação do edema peritumoral. Geralmente administra-se doses de 4 Gy por três a cinco dias por semana durante três a quatro semanas, totalizando 48 Gy. É uma opção dispendiosa e pouco acessível, mas confere um bom prognóstico, aumentado a expectativa de vida do cão. A resolução dos sinais clínicos ocorre paralelamente à redução do tamanho do tumor, que pode continuar diminuindo até um ano após o fim do tratamento; a redução da secreção de ACTH pode demorar de seis a 12 meses (HERRTAGE; RAMSEY, 2015; NELSON, 2015).

\section{PROGNÓSTICO}

O prognóstico depende da abordagem terapêutica, da idade do animal, do estado geral e da monitoração que este animal recebe (REINE, 2007). Segundo Peterson e Kintzer (2008) o prognóstico do HAC é sempre reservado, pois há várias complicações associadas à doença que aparecem nos primeiros três a seis meses após o diagnóstico, e os cães que sobrevivem a esse período tipicamente morrem em razão de outros distúrbios geriátricos.

Segundo Nelson (2015), cães que apresentam o HAC e são tratados apresentam o prognóstico bom tendo uma sobrevida média de 30 a 36 meses. Reine (2007) relatou que a expectativa média de vida no tratamento com mitotano é de 708 dias, enquanto com trilostano é de 662 dias após o início da terapia. Já De Marco (2015), relata que a expectativa de vida é a mesma para animais tratados com ambos fármacos, podendo varia de 2 a 4 anos e ser maior em animais jovens, devido aos menores riscos de apresentarem doenças geriátricas concomitantes.

No caso de tumor adrenal, cães com adenoma adrenocortical ou carcinoma adrenocortical não metastatizado (incomum) têm bom prognóstico, enquanto os cães com carcinoma adrenocortical metastático ou carcinoma com invasão venosa (comum) têm prognóstico pior e geralmente morrem em um a dois anos depois do diagnóstico.

No HPD a sobrevida média é de 30 meses se não houver complicações secundárias, porém, se a causa do HPD for um macroadenoma hipofisário, o prognóstico é reservado, pois este geralmente é extenso e comprime estruturas adjacentes (NELSON, 2015),

\section{CONSIDERAÇÕES FINAIS}

O hiperadrenocorticismo possui sintomatologia inespecífica que muitas vezes pode passar despercebida por acometer animais mais velhos e ser confundida com as complicações da senilidade. Em grande parte dos casos o proprietário procura 0 médico veterinário em decorrência das alterações dermatológicas.

O diagnóstico é complexo pois requer que sejam seguidas várias etapas, como diagnóstico presuntivo, exclusão de outras enfermidades, diagnóstico confirmatório e investigação etiológica. Apesar da disponibilidade de muitas ferramentas, o consenso é que seja feito o TeACTH como método de triagem e o TSDDB como confirmatório.

No Brasil o tratamento mais utilizado é o clínico. O trilostano tem sido a droga de escolha e pode ser manipulado ou adquirido como Vetoryl®, que já se encontra disponível no mercado nacional. O sucesso do tratamento está diretamente relacionado à adesão do proprietário, uma vez que a administração do fármaco é 
diária e o tratamento é dispendioso. Apesar de existirem as opções cirúrgicas, a hipofisectomia só é realizada nos Estados Unidos e na Europa e a adrenalectomia é raramente realizada no Brasil.

O prognóstico está intimamente relacionado com a etiologia do HAC em questão e com a monitoração adequada do animal.

\section{REFERÊNCIAS}

BEHREND, E. N. Canine hyperadrenocorticism (Cushing's Syndrome). In: FELDMAN, E. C.; NELSON, R.W.; REUSCH, C.; SCOTT-MONCRIEFF, J. C.; BEHREND, E. Canine and Feline Endocrinology. 4.ed. St. Louis, Missouri: Saunders, 2015. p. 377-444.

BEHREND, E. N.; KEMPPAINEN, R. J. Diagnosis of canine hyperadrenocorticism. Veterinary Clinics of North America: Small Animal Practice, v. 31, n. 5, p. 9851003, 2001. Disponível em: < https://doi.org/10.1016/S0195-5616(01)50009-1>. doi: $10.1016 /$ S0195-5616(01)50009-1

BEHREND, E. N.; KOOISTRA, H. S.; NELSON, R.; REUSCH, C. E.; SCOTTMONCRIEFF, J. C. Diagnosis of Spontaneous Canine Hyperadrenocorticism: 2012 ACVIM Consensus Statement (Small Animal). Journal of Veterinary Internal Medicine. v. 27, n. 6, p.1292-1304, 2013.

BEHREND, E. N.; MELIAN, C. Hyperadrenocorticism in dogs. In: BEHREND E. N.; GUNN-MOORE, D.; CAMPBELL-WARD, M. Clinical Endocrinology of Companion Animals. Ames: Wiley-Blackwell, 2013. p. 43-64.

DE MARCO, V. Hiperadrenocorticismo canino. In: JERICO, M. M.; KOGIKA, M. M.; ANDRADE, J. P. Tratado de medicina interna de cães e gatos. Rio de Janeiro: Roca, 2015. p. 1691-1703.

DE MARCO, V. Hiperadrenocorticismo. In: LARSSON, C. E.; LUCAS, R. (Ed.). Tratado de medicina interna: dermatologia veterinária. São Caetano do Sul: Interbook, 2016. p. 575-592.

ETTINGER, S. J.; FELDMAN, E. C. Tratado de Medicina Interna Veterinária: doenças do cão e do gato. 5.ed. Rio de Janeiro: Guanabara Koogan, 2004. 2156 p.

FELDMAN, E. C., NELSON, R.W.; REUSCH, C.; SCOTT-MONCRIEFF, J. C. R.; BEHREND, E. N. 2015. Canine and Feline Endocrinology. W.B Saunders, St Louis, MO. 669p

FOSSUM, T. W.; CAPLAN, E. R. Cirurgia do Sistema Endócrino. In: FOSSUM, T. W. Cirurgias de Pequenos Animais. 4.ed. Rio de Janeiro: Elsevier, 2014. p. 637-646.

GONZALÉZ, F. H. D.; SILVA, S.C. Introdução à Bioquímica Clínica Veterinária. Porto Alegre: UFRGS, 2003. $198 \mathrm{p}$.

HERRTAGE, M. E.; RAMSEY, I. K. Hiperadrenocorticismo em Cães. In: MOONEY. C. T.; PETERSON, M. E. Manual de Endocrinologia em Cães e Gatos. 4.ed. São 
Paulo: Roca, 2015. p. 254-289.

KLEIN, B. G. Glândulas Endócrinas e Suas Funções. In: KLEIN, B. G. Cunningham Tratado de Fisiologia Veterinária. 5.ed. Rio de Janeiro: Elsevier, 2014.

KOOISTRA, H. S., GALAC, S. Recent advances in the diagnosis of Cushing's syndrome in dogs. Veterinary Clinics of North America: Small Animal Practice, v. 40, n. 2, p. 259-267, 2010. Disponível em: < https://www.ncbi.nlm.nih.gov/pubmed/ 20219487>. doi: 10.1016/j.cvsm.2009.10.002

MARTINS, R. C. B.; JERICÓ, M. M. Uso de baixa dose de ACTH sintético no teste de estimulação da função adrenal para 0 diagnóstico e controle do hiperadrenocorticismo canino: avaliação da eficácia diagnóstica. Pesquisa Veterinária Brasileira, v. 37, n.3, p. 241-247, março 2017. Disponível em: < http://dx.doi.org/10.1590/s0100-736x2017000300007> doi: 10.1590/S0100-736X201 7000300007

NELSON, R. W. Distúrbios da Glândula Adrenal. In: NELSON, R. W.; COUTO, C. G. Medicina interna de pequenos animais. 5.ed. Rio de Janeiro: Elsevier, 2015. p. 824-862.

MILLER, W.H.; GRIFFIN, C.E.; CAMPBELL, K.L. Muller \& Kirk's Small animal dermatology. 7 th ed. St. Louis: Elsevier Mosby, 2013.

NYLAND, T. G.; MATTOON, J. S.; HERRGESELL, E. J.; WISNER, E. R. (2005). Glândulas adrenais. In: NYLAND, T. G.; MATTOON, J. S. Ultra-Som, Diagnóstico em Pequenos Animais. 2.ed. São Paulo: Editora Roca, 2005. p. 200-208.

PACINI, T.; NISHIYA, A. T.; SCALIZE, L. P.; JERICÓ, M. M. Estudo Retrospectivo dos Casos de Adrenalectomia Realizados no Hospital Veterinário da Universidade Anhembi Morumbi: 13 casos (2012 a 2015). Revista de Educação Continuada em Medicina Veterinária e Zootecnia, v. 13, n. 2, 2015. Disponível em: <https://doi.org/10.11606/issn.1678-4456.bjvras.2017.109471>. doi: 10.1590/S010073 6X2017000300007

PÉREZ-ALENZA, D.; MELIÁN, C. Hyperadrenocorticism in Dogs. In: ETTINGER, S. J.; FELDMAN, E. C.; CÔTE, E. Textbook of Veterinary Internal Medicine. 8. ed. Rio de Janeiro: Elsevier, 2017. p. 4345

PETERSON M. E. Diagnosis of Hyperadrenocorticism in Dogs. Clinical Techniques in Small Animal Practice, v. 22, n.1, p. 2-11, 2007. Disponível em: < https://www.sciencedirect.com/science/article/pii/S1096286707000084>. doi: 10.105 3/j.ctsap.2007.02.007

PETERSON, M. E.; KINTZER, P. P. Doenças da Glândula Adrenal. In: BIRCHARD, S. J.; SHERDING, R. G. Manual Saunders Clínica de Pequenos Animais. 3.ed. São Paulo: Roca, 2008. p. 363-380. 
PÖPPL, A. G. Adrenalectomia laparoscópica no tratamento cirúrgico do hiperadrenocorticismo em cães: um desafio para a medicina veterinária. Medvep Revista Científica de Medicina Veterinária, v. 7, p. 37-43, 2009. Disponível em: $<$ https://www.researchgate.net/publication/292681808_Adrenalectomia_laparoscopic a_no_tratamento_cirurgico_do_hiperadrenocorticismo_em_caes_um_desafio_para a_medicina_veterinaria_Hiperadrenocorticism_surgical_treatment_by_laparoscopic adrenalectomy_in_?enrichld=rgreq16485f575dd0b5d4c46f952a8520c10dXXX\&enri chSource=Y292ZXJQYWdlOzI5MjY4MTgwODtBUzozMjQ2NzUyOTU0ODE4NTZAM TQ1NDQyMDAzMDMxNg\%3D\%3D\&el=1_x_2\&_esc=publicationCoverPdf>.

PÖPPL, A. G.; COELHO, I. C.; SILVEIRA, C. A.; MORESCO, M. B.; CARVALHO, G. L. Frequency of Endocrinopathies and Characteristics of Affected Dogs and Cats in Southern Brazil (2004-2014). Acta Scientiae Veterinariae, Porto Alegre, v. 44 pub. 1379. p. 1-9. 2016. Disponível em: <http://www.ufrgs.br/actavet/44/PUB\%201379.pd $\mathrm{f}>$.

REINE N. Medical Management of Pituitary Dependent Hyperadrenocorticism: Mitotane vs Trilostane. Clinical Techniques in Small Animal Practice, v. 22, n.1, p. 18-25, 2007. Disponível em:<https://doi.org/10.1053/j.ctsap.2007.02.003>. doi: 10.1 053/j.ctsap.2007.02.003

ROMÃO, F. G.; LEITÃO, L. M. M.; MACHADO, L. H. A.; LOURENÇO, M L. G.; MAMPRIM, M. J.; et al. Hiperadrenocorticismo em Cães - Revisão. Clínica Veterinária. a. 16, n. 91, p. 86-92, 2011. Disponível em: $<$ http://hdl.handle.net/11449/137037>.

SOULSBY, S. N.; HOLLAND, M.; HUDSON, J. A.; BEHREND, E. N. Ultrasonographic evaluation of adrenal gland size compared to body weight in normal dogs. Veterinary Radioliology Ultrasound, v. 56, n. 3, p. 317-326, 2015. Disponível em: < https://doi.org/10.1111/vru.12236>. doi: 10.1111/vru.12236 